Authors' Contribution: A Study Design B Data Collection C Statistical Analysis D Data Interpretation E Manuscript Preparation F Literature Search G Funds Collection

\section{Relationships between motor abilities and volleyball performance skills in 15-year-old talent-identified volleyball players}

\author{
Dariusz Mroczek $^{\mathrm{ADEF}}$, Edward Superlak ${ }^{\mathrm{ABD}}$, Adam Kawczyński ${ }^{\mathrm{CEF}}$, Jan Chmura ${ }^{\mathrm{AD}}$ \\ Department of Biological and Motor Sport Bases, Faculty of Sport Science, University \\ School of Physical Education, Wrocław, Poland
}

\section{abstract}

Background

Material/Methods

Results

Conclusions

Key words
The aim of this study is to determine synergistic motor outcomes understood as sets of mutually dependent players' motor abilities affecting the efficacy of performance skills of young volleyball players.

The study was carried out during a national volleyball tournament for 150 boys aged 14-15 years. The matches were recorded with two cameras placed $10 \mathrm{~m}$ behind the end line, $1.6 \mathrm{~m}$ above the floor. The following parameters were assessed: attack efficacy, block efficacy, serve efficacy. The first dependent variables were players' actions that most significantly affected the set outcome, i.e. serves, blocks and attacks.

The greatest differences were found among players' serve results, where - with the exception of ineffective serves - the index of variability ranged from $v=67.14$ (countereffective serve) to $v=80.23$ (effective serve).

The study showed that serving and attacking effectiveness is directly determined by standing jumping ability, while blocking efficacy is affected by the height of the running vertical jump.

volleyball, performance skills analysis, game efficacy

\section{article details}

Article statistics

Full-text PDF:

Copyright

Indexation:

Funding:

Conflict of interest: Corresponding author:

Open Access License:
Word count: 3,471; Tables: 4; Figures: 1; References: 22

Received: January 2016; Accepted: December 2016; Published: March 2017

http://www.balticsportscience.com

(๑) Gdansk University of Physical Education and Sport, Poland

AGRO, Celdes, CNKI Scholar (China National Knowledge Infrastructure), CNPIEC, De Gruyter - IBR (International Bibliography of Reviews of Scholarly Literature in the Humanities and Social Sciences), De Gruyter - IBZ (International Bibliography of Periodical Literature in the Humanities and Social Sciences), DOA), EBSCO - Central $\&$ Eastern European Academic Source, EBSCO - SPORTDiscus, EBSCO Discovery Service, Google Scholar, Index Copernicus, J-Gate, Naviga (Softweco, Primo Central (ExLibris), ProQuest - Family Health, ProQuest - Health \& Medical Complete, ProQuest - Illustrata: Health Sciences, ProQuest - Nursing \& Allied Health Source, Summon (Serials Solutions/ProQuest, TDOne (TDNet), Ulrich's Periodicals Directory/ulrichsweb, WorldCat (OCLC)

\section{sectors.}

Authors have declared that no competing interest exists.

Prof. dr hab. Jan Chmura, Department of Biological and Motor Sport Bases, University School of Physical Education, Al. I.J. Paderewskiego 35, 51-612 Wroclaw, Poland; email: jan.chmura@awf.wroc.pl; tel: +48713743390

This is an open access article distributed under the terms of the Creative Commons Attribution-Non-commercial 4.0 International (http://creativecommons.org/licenses/by-nc/4.0/), which permits use, distribution, and reproduction in any medium, provided the original work is properly cited, the use is non-commercial and is otherwise in compliance with the license. 


\section{INTRODUCTION}

The game of volleyball is characterized by a great number of changing situations in which players perform a variety of actions attempting to score points, while avoiding making errors and losing points, which obviously leads to a conflict of aims [1]. The match outcome depends on a variety of gameplay elements, and the score depends on the quality of attacks, blocks, serves and the number of the opponent's errors [2-11].

Volleyball players at the net usually perform their attacks and blocks high above the net. The players' maximal reach ability in running jumps in attacks and in standing jumps in blocks is decisive for their effective actions [12]. This ability is an important indicator in the process of selecting young volleyball players. Hermoso et al. [13] in their study of 14-15-year-old volleyball players revealed significant differences between won and lost volleyball sets, based on the degree of players' serve, dig and spike efficacy. Conti et al. [6] observed that scoring opportunities in elite volleyball youth teams were significantly affected by quick and powerful attacks.

A player's dynamic force and speed of locomotion are dominant in attacks and blocks, which in most cases decide about the set outcome [14]. Many authors $[15,16,17]$ stress the importance of the vertical jump (one-foot or two-foot; standing or running; with or without a semi-squat) which requires a high level of explosive muscle force.

A successful preparation process of volleyball players requires constant gathering of information about the effectiveness of their actions during games. According to Miskin et al. [18], volleyball coaches should estimate different performance skills of individual players during sets and matches and then adjust the training cycle of the team concentrating on the development of the efficacy of key skills that significantly determine players' scoring abilities.

Authors of relevant studies have mostly focused on the determination of relationships between particular motor skills of volleyball players and their attacking, blocking and serving efficacy influencing the set outcome [15, 16, 17]. Many of these authors have stressed, first of all, the correlations between individual players' abilities and particular elements of volleyball gameplay. Stronger correlations have been mostly interpreted as motor determinants of players' high efficacy of actions.

However, the available literature lacks reports on relationships between whole sets of volleyball motor skills and performance efficacy. It seems that relationships between particular motor abilities and playing efficacy are multidimensional and involve different directions and strengths of correlations.

The aim of this study is the determination of synergistic motor outcomes understood as sets of mutually dependent players' motor abilities affecting the efficacy of performance skills of young volleyball players. We hypothesized that attack efficacy, block efficacy and serve efficacy are determined by particular motor abilities. 


\section{MATERIAL AND METHODS}

\section{SUBJECTS}

The study was carried out during a national volleyball tournament for 150 boys aged 14-15 years. After completion of the tournament, expert coaches assessed the players' motor abilities and volleyball performance skills, and identified the most talented players for further training. It must be underlined that six experts coaches were chosen by the Polish National Volleyball Association. All experts were highly qualified, professional coaches contracted in Polish national and extra league teams.

After a long training process in sports clubs and in the Athletic Championship School of the Polish Volleyball Federation, the Poland national coach finally selected 12 players for the Poland Boys' Youth National Volleyball Team, including two setters, three middle blockers and seven hitters. In 2005 the Polish team won the Boys' Youth European Championship in Riga, Latvia.

The selected boys' training experience (i.e. their active and systematic participation in training and competitions) ranged from 3 to 4 years. The 12 elite players constituted a representative sample for the Polish population of volleyball players aged 15 years. Table 1 presents the players' anthropometric data. The players were informed about the purpose of the study before its commencement, and their parents or guardians gave their informed written consent to participate in the study. All matches during the tournament were recorded. In the present study only players who won Boys' Youth European Championship in Riga, Latvia, were involved in the effectiveness analysis.

Table 1. Anthropometric data of selected volleyball players

\begin{tabular}{|c|c|c|c|c|c|c|}
\hline Player & Position & $\begin{array}{l}\text { Body } \\
\text { height } \\
{[\mathrm{cm}]}\end{array}$ & $\begin{array}{l}\text { Body } \\
\text { mass } \\
{[\mathrm{kg}]}\end{array}$ & $\begin{array}{l}\text { Ponderal } \\
\text { Index } \\
\text { (PI) }\end{array}$ & $\begin{array}{c}\text { Standing } \\
\text { one-arm reach } \\
{[\mathrm{cm}]}\end{array}$ & $\begin{array}{c}\text { Standing } \\
\text { two-arm reach } \\
{[\mathrm{cm}]}\end{array}$ \\
\hline 1. & hitter & 187 & 77 & 1.13 & 248 & 246 \\
\hline 2. & hitter & 188 & 70 & 1.05 & 252 & 247 \\
\hline 3. & hitter & 190 & 80 & 1.17 & 258 & 252 \\
\hline 4. & hitter & 187 & 74 & 1.13 & 242 & 238 \\
\hline 5. & hitter & 202.5 & 89 & 1.07 & 265 & 260 \\
\hline 6. & hitter & 185 & 65 & 1.03 & 246 & 241 \\
\hline 7. & hitter & 190 & 69 & 1.01 & 254 & 250 \\
\hline 8. & middle blocker & 197 & 90 & 1.18 & 262 & 256 \\
\hline 9. & middle blocker & 191 & 70 & 1 & 250 & 248 \\
\hline 10. & middle blocker & 191 & 63 & 0.9 & 254 & 251 \\
\hline 11. & setter & 184 & 68 & 1.09 & 242 & 238 \\
\hline 12. & setter & 179 & 69 & 1.2 & 237 & 234 \\
\hline \multicolumn{2}{|c|}{ Mean (M) } & 189.3 & 73.7 & 1.1 & 250.8 & 246.8 \\
\hline \multicolumn{2}{|c|}{ Standard deviation (SD) } & 6.1 & 8.8 & 0.1 & 8.4 & 7.8 \\
\hline \multicolumn{2}{|c|}{ Index of variability (v) } & 3.2 & 11.9 & 9.1 & 3.3 & 3.2 \\
\hline
\end{tabular}




\section{METHODS}

The aim of the tournament was to select the best candidates for the Polish youth national team before the Boys' Youth Volleyball European Championship. During the qualifying stage expert volleyball coaches (qualifications described in methods) observed all the participating players and selected the most talented and skillful ones to teams that would advance to the final stage of the tournament. All the matches between the selected teams were then video recorded during the final stage of the tournament.

The subjects gave their written consent prior to the study, which was approved by the local Ethics Committee in University of Physical Education in Wrocław, Poland and accords with the Helsinki Declaration.

During the tournament the selected young players were subjected to exercise tests assessing the levels of their motor skills. The tests included:

- a running vertical jump with a one-arm swing;

- a standing vertical jump with a two-arm swing;

- a $3 \mathrm{~kg}$ medicine ball throw;

- a 10-m run;

- a zig-zag run.

\section{PROCEDURES}

The matches were recorded with two Sony DCR-SR70E video cameras with a VCL-060X x 0.6 wide conversion lens. The two cameras were each placed $10 \mathrm{~m}$ behind the end line, $1.6 \mathrm{~m}$ above the floor. The analysis of the recorded footage consisted of re-playing of each action of the computer screen. The following efficacy scale was used to determine the players' volleyball performance skills:

Attack efficacy:

- Effective - action completed, point scored;

- Ineffective - attack defended, game continues;

- Counter-effective - action completed, error in attack, point awarded to the opposing team.

Block efficacy:

- Effective - action completed, attack blocked, point scored;

- Ineffective - attack defended after the ball is ineffectively blocked, game continues;

- Counter-effective - action completed, error in block, point awarded to the opposing team.

Serve efficacy:

Effective - action complete, "ace", point scored;

Ineffective - serve received by the opposing team, game continues;

Counter-effective - action completed, error in block, point awarded to the opposing team.

The following self-authorized formula was used to calculate the index of serve (overhand, jump float or power), jump block and attack efficacy, (i.e. ISE, IBE, IAE) being the quotient of the sum of effective actions and the sum of all actions performed by each player: 
$\mathrm{IE}=$

$\sum$ of effective actions

$\sum$ of effective actions $+\sum$ of ineffective actions $+\sum$ of counter-effective actions

The index of efficacy values ranged between 0.0-1.0. A higher index value (closer to 1.0) signified a higher level of player's efficacy. The indices were prepared by authors of the present study.

The tests measuring the players' motor abilities were chosen and approved by a group of independent expert coaches appointed by the Polish Volleyball Federation.

The battery of motor skills tests used in the study included:

- running jump with a one-arm swing (dynamic force of the legs) - the best result out of three trials was recorded down. Each player began the test with a 3-4 m run-up, and then took a two-foot vertical jump and attempted to touch with the dominant extended arm the highest possible point on the measurement stand [cm].

- standing jump with a two-arm swing (dynamic force of the legs) - the best result out of three trials was recorded down. Each player began the test by standing on both feet. After lowering the body center of mass (bending the knees, leaning the body forward and taking a two-arm swing) the player performed a vertical jump and attempted to touch with extended arms the highest possible point on the measurement stand [cm]. If the players' hands touched the stand in an non-parallel manner, the measurement point touched by the higher hand was taken into account.

- running jumping ability(dynamic force of the legs) - the difference between the height of one-arm reach in a running jump and standing one-arm reach [cm];

- standing jumping ability (dynamic force of the legs) - the difference between the reach of two arms in a standing vertical jump and standing two-arm reach $[\mathrm{cm}]$;

- $3 \mathrm{~kg}$ medicine ball throw (dynamic force of the arms) - the $3 \mathrm{~kg}$ ball was thrown overhead forward using both arms. During the throw a player was kneeling on a mattress and maintained the body balance. The best result out of three trials was recorded down [m];

- $10 \mathrm{~m}$ run - a player began the test in prone position with the shoulders along the starting line. On a signal with a downward movement of the starting flag the player stood up and began running crossing the starting line and the $10 \mathrm{~m}$ finishing line, each marked by two pairs of photo-sensors. The best result out of three trials was recorded down [sec].

- zig-zag run (Fig. 1) (7 m x 7 m "envelope" test) [sec] - a player began the test in prone position with the shoulders along the starting line, and with the hands at the line of the shoulders:

- the timer was started once the player began extending his arms;

- the player ran forward toward the net and then ran backward away from the net facing the net all the time;

- the timer was stopped once the player had crossed the center line.

The running route was marked with five flags 7 meters apart. The covered distance was measured in seconds. 


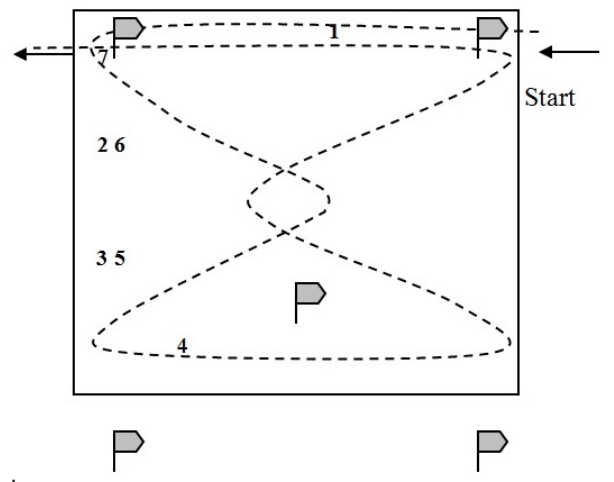

Fig.1. The zig-zag test route

\section{STATISTICAL ANALYSIS}

Multiple regression analysis was used to determine the relationships between several independent variables and a dependent variable. The independent variables included the motor abilities test results, while the dependent variables were the indices of efficacy of particular volleyball performance skills. The most appropriate subset of independent variables for a given dependent variable was found by calculating $\mathrm{R}^{2}$ values and standardized regression coefficients (ß) for each subset pattern.

In the analysis of collinearity for regression equation expressions, with parametrization with sigma-limits, a partial correlation was estimated for each variable, between a given variable and a dependent variable (after having considered the impact of all remaining independent variables), t-test values and the level of statistical significance $p(0.0001<\alpha<0.05)$.

\section{RESULTS}

\section{VOLLEYBALL PERFORMANCE SKILLS}

The first dependent variables were players' actions that most significantly affected the set outcome, i.e. serves, blocks and attacks (Tab. 2). The greatest differences were found among players' serve results, where - with the exception of ineffective serves - the index of variability ranged from $\mathrm{v}=67.14$ (countereffective serve) to $\mathrm{v}=80.23$ (effective serve).

The relatively lowest variability, however within the widest range, was found among attack results: from $v=14.07$ (effective attack, low variability) to $\mathrm{v}$ $=66.42$ (counter-effective attack, very high variability). In terms of block efficacy the differences ranged from $v=42.74$ to $v=55.59$. The variability index for the counter-effective block exceeding 100\% ( $v=133.19)$ requires some explanation. No counter-effective blocking actions were recorded by six players, while in the case of the other six players they ranged from 1 to 6 . Thus the standard deviation $(S=2.11)$ was higher than the mean value $(M=1.58)$. 
Table 2. Efficacy of serving, blocking and attacking performance skills

\begin{tabular}{|c|c|c|c|c|c|c|}
\hline Volleyball action & Level of efficacy & $\begin{array}{l}\text { Mean } \\
M\end{array}$ & $\begin{array}{l}\text { Standard } \\
\text { deviation S }\end{array}$ & Min & Max & $\begin{array}{c}\text { Index of } \\
\text { variability } \\
v\end{array}$ \\
\hline \multirow{4}{*}{ Serve } & effective & 3.58 & 2.87 & 0 & 9 & 80.23 \\
\hline & ineffective & 15.17 & 4.95 & 9 & 27 & 32.65 \\
\hline & counter-effective & 3.67 & 2.46 & 0 & 9 & 67.14 \\
\hline & $\begin{array}{l}\text { index of serving efficacy } \\
\text { (ISE) }\end{array}$ & 0.13 & 0.09 & 0 & 0.25 & 69.87 \\
\hline \multirow{4}{*}{ Block } & effective & 2.92 & 1.62 & 0 & 6 & 55.59 \\
\hline & ineffective & 10.17 & 4.34 & 3 & 16 & 42.74 \\
\hline & counter-effective & 1.58 & 2.11 & 0 & 6 & 133.19 \\
\hline & $\begin{array}{l}\text { index of blocking efficacy } \\
\text { (IBE) }\end{array}$ & 0.23 & 0.14 & 0 & 0.5 & 59.42 \\
\hline \multirow{4}{*}{ Attack } & effective & 11.42 & 5.87 & 2 & 24 & 51.41 \\
\hline & ineffective & 9.58 & 4.44 & 4 & 15 & 46.34 \\
\hline & counter-effective & 4.08 & 2.71 & 0 & 9 & 66.42 \\
\hline & $\begin{array}{l}\text { index of attacking } \\
\text { efficacy (IAE) }\end{array}$ & 0.45 & 0.06 & 0.29 & 0.53 & 14.07 \\
\hline
\end{tabular}

The highest mean number of points was scored by spiking $(M=11.42 \mathrm{pts})$, followed by serving ( $\mathrm{M}=3.58$ pts.) and by blocking $(M=2.92 \mathrm{pts}$.) $(\mathrm{IAE}=$ 0.45 ; IBE $=0.23$; ISE $=0.13$ ).

\section{MOTOR ABILITIES}

The regression analysis permitted the selection of the most appropriate subset of motor abilities that were significantly correlated with effective serves, blocks or attacks (Tab. 3).

Table 3. Regression coefficients $\left(R^{2}\right)$ for particular subsets of motor abilities and volleyball performance skills

\begin{tabular}{|c|c|c|c|c|c|c|c|c|c|}
\hline \multirow[b]{2}{*}{$\begin{array}{l}\text { Volleyball } \\
\text { action }\end{array}$} & \multirow[b]{2}{*}{$\begin{array}{l}\text { Index of } \\
\text { efficacy }\end{array}$} & \multirow[b]{2}{*}{$R^{2}$} & \multicolumn{7}{|c|}{ Motor abilities test } \\
\hline & & & $\begin{array}{l}\text { Running jump } \\
\text { height with } \\
\text { a one-arm } \\
\text { swing }\end{array}$ & $\begin{array}{l}\text { Standing jump } \\
\text { height with a } \\
\text { two-arm swing }\end{array}$ & $\begin{array}{l}\text { Running } \\
\text { jumping } \\
\text { ability }\end{array}$ & $\begin{array}{l}\text { Standing } \\
\text { jumping } \\
\text { ability }\end{array}$ & $\begin{array}{c}3 \mathrm{~kg} \\
\text { medicine } \\
\text { ball throw }\end{array}$ & $\begin{array}{l}\text { Zig-zag } \\
\text { run }\end{array}$ & $\begin{array}{c}10 \mathrm{~m} \\
\text { run }\end{array}$ \\
\hline \multirow{3}{*}{ Serve } & effective & 0.68 & -0.60 & & & 0.65 & -0.73 & & \\
\hline & \multirow{2}{*}{ ISE } & 0.79 & & & & 0.36 & -1.13 & & \\
\hline & & 0.77 & -0.45 & & & 0.53 & -0.89 & & \\
\hline Block & IBE & 0.88 & 2.04 & & -0.91 & & & & \\
\hline \multirow{2}{*}{ Attack } & effective & 0.66 & & & & 1.32 & & 1.04 & \\
\hline & IAE & 0.81 & & & 0.63 & & & & \\
\hline
\end{tabular}

Effective serves performed by the players were strongly correlated $\left(R^{2}=0.68\right)$ with a subset of three motor abilities: standing jumping ability, running jump with a one-arm swing and the dynamic force of the shoulder girdle (for the last two abilities the correlation was negative). All three types of serve efficacy (as indicated by the IE) were correlated with a subset of two motor abilities: standing jumping ability, the dynamic force of the shoulder girdle $\left(R^{2}=0.79\right)$ and the running jump with a one-arm swing $\left(R^{2}=0.77\right)$. 
The block efficacy (IBE) was significantly correlated $\left(R^{2}=0.88\right)$ with a subset of running jump with a one-arm swing and running jumping ability. Effective scoring with attacks was correlated $\left(R^{2}=0.66\right)$ with the standing jumping ability and the zig-zag run test results. However, the index of attack efficiency (IAE) was greatly determined only by the running jumping ability $\left(R^{2}=0.81\right)$.

Table 4 shows correlations between dependent variables (efficiency of volleyball performance skills) and independent variables (motor abilities) at $\alpha<0.05$.

The serve efficiency was significantly correlated with standing jumping ability (0.69), but was not correlated with the height of the running jump with a one-arm swing $(-0.68)$ or the dynamic force of the shoulder girdle muscles $(-0.77)$. The negative effect of the last motor ability was confirmed by its strong correlation with the index of serve efficiency (-0.89) and a high t-value (-5.42).

Table 4. Correlations between efficiency of volleyball performance skills and motor abilities

\begin{tabular}{|c|c|c|c|c|}
\hline Volleyball action & Motor abilities test & $\begin{array}{c}\text { Partial } \\
\text { correlation } \\
\end{array}$ & $\mathrm{t}$ & $p$ \\
\hline \multirow{6}{*}{ Serve } & \multicolumn{4}{|c|}{ Effective serve } \\
\hline & Running jump with a one-arm swing & -0.68 & -2.63 & 0.0301 \\
\hline & Standing jumping ability & $0.69 *$ & 2.66 & 0.0286 \\
\hline & $3 \mathrm{~kg}$ medicine ball throw & -0.77 & -3.36 & 0.0099 \\
\hline & \multicolumn{4}{|c|}{ Index of serving efficacy (ISE) } \\
\hline & $3 \mathrm{~kg}$ medicine ball throw & -0.89 & -5.42 & 0.0006 \\
\hline & Index of blocki & $(\mathrm{IBE})$ & & \\
\hline \multirow[t]{4}{*}{ Block } & Running jump with a one-arm swing & $0.93 *$ & 7.02 & 0.0001 \\
\hline & running jumping ability & -0.84 & -4.46 & 0.0021 \\
\hline & \multicolumn{4}{|c|}{ Effective attack } \\
\hline & Standing jumping ability & $0.81^{*}$ & 3.91 & 0.0045 \\
\hline \multirow[t]{3}{*}{ Attack } & Zig-zag run & 0.74 & 3.07 & 0.0153 \\
\hline & \multicolumn{4}{|c|}{ Index of attacking efficacy (IAE) } \\
\hline & Running jumping ability & $0.82 *$ & 4.06 & 0.0036 \\
\hline
\end{tabular}

* statistically significant differences $(p<0.05)$

The partial correlation value indicated a strong correlation between the index of block efficacy (IBE) and the height of the running jump with a one-arm swing $(0.93 ; t=7.02)$, but not between the IBE and the running jumping ability $(-0.84$; $t=-4.46)$. The attack efficacy was significantly determined by a high level of the standing jumping ability (0.81), while it was not significantly correlated with the zig-zag rune test results (0.74). The general attack efficacy (IAE) was largely dependent on the running jumping ability (0.82).

\section{DISCUSSION}

The results of the analysis showed that volleyball players' efficacy determined to a large degree, although in various ways, the players' levels of motor abilities.

The study revealed that the effective performance of attacks, blocks and serves was correlated with various motor abilities and formed specific subsets with these abilities. An effective serve performance is correlated with a set consisting of the standing jumping ability, the running jump with a one-arm 
swing and $3 \mathrm{~kg}$ medicine ball throw; an effective block performance -with a set of the height of the running jump with a one-arm swing, the running jumping ability and the speed of locomotion with changing directions (zig-zag run).

Studies on relationships between attack, block and serve efficacy in volleyball with players' motor abilities have been carried out by a number of authors [16, 19]. According to Dopsaj et al. [20], power, strength and speed are important determinants of spike and block jumps and are decisive for the set outcome. Significant correlations between effective blocks and the set outcome in male volleyball players were also revealed by Palao et al. [21].

In their study of relationships between motor abilities and volleyball performance Dopsaj et al. [14] concluded that players' dynamic force and locomotion speed are dominant in attacks and blocks and in most cases are decisive for the set outcome.

On the other hand, a study of 14-15 and 16-17-year-old female volleyball players by Katić et al. [12] showed that attacks and blocks were the best predictors of game scores, and their analysis of regression revealed a correlation between players' force and speed; however, the former had a greater impact on the set outcome than the latter. Conti et al. [6] concluded that youth volleyball gameplay becomes more offensive in result of the performance of attacks by players with high levels of dynamic force, and the force and the speed of attacks do increase chances of scoring. Marcelino et al. [9] noted that the spike is the best index of the volleyball set outcome, followed by the block. The best volleyball teams do have the largest number of serve errors, but also gain more points by the opponent's serve errors. The study results of Zetou et al. [5] confirm that "ace" volleyball serves are important tools of victory of aggressive teams.

Particular volleyball actions can be assigned respective indices of efficacy. In the present study these indices were 0.45 for attacks, 0.23 for blocks, and 0.13 for serves. Similar volleyball efficacy indices (in \%) were examined by Monteiro et al. [11], and they amounted to $13.67 \%$ for the serve (corresponding to the results of the present study), $29.17 \%$ for the spike, and $6.49 \%$ for the block. The last two indices were lower than their counterparts in the present study.

Lidor and Ziv [22] in their multidimensional assessment of determinants of volleyball game play in young players emphasized the significance of the vertical jump for the set outcome and recommended selection of appropriate tests to assess young volleyball players' skills and abilities.

\section{CONCLUSIONS}

The results of the present study can be directly used in the development of training programs by volleyball coaches of young players. They clearly indicate that serving and attacking effectiveness is directly determined by the standing jumping ability, while blocking efficacy is affected by the height of the running vertical jump. This necessitates the consideration of diversified of hitter, middle blocker and setter selection criteria in volleyball. A hitter and setter must possess a high level of standing jumping ability, while a middle blocker a long arm reach in a running vertical jump. 
The authors hope that this pioneering study will encourage others to design and apply more innovative and efficient methods of measuring motor abilities and volleyball performance skills.

\section{PRACTICAL IMPLICATION}

The obtained results allow giving important information to trainers. Effective serve does not depend on a large dynamic force of the shoulder girdle; actually, the progressive development of the shoulder girdle can even cause a decrease in the effectiveness of the serve. This should be taken into a consideration while planning training for a player.

The study confirmed the practical rule, very often used by trainers, that the position of the player in the middle block, is reserved for a person with the best result in the running vertical jump. This parameter has a significant impact on the high performance reliability for activities in the block.

The most reliable players in attack turned out to be those with the highest values of the jumping ability (immediately and with the run up) and the speed of shift. Therefore, it is the dynamic force of the players' lower limbs that has the most significant impact on the effectiveness of attack not the standing jumping ability. It is possible to suggest that the position of the receiving or attacking player should be assigned to players with this particular motoric abilities.

\section{ACKNOWLEDGEMENT}

The authors wish to thank the Polish Volleyball Federation for its assistance at the tournament.

\section{REFERENCES}

[1] Afonso J, Esteves F, Araújo R, Thomas L, Mesquita I. Tactical determinants of setting zone in elite men's volleyball. J Sport Sci Med. 2012;11:64-70.

[2] Zetou E, Moustakidis A, Tsigilis N, Komninakidou A. Does effectiveness of skill in complex I predict win in Men’s Olympic Volleyball Games? J Quant Anal Sport. 2007;3:1-11.

[3] Yiannis L, Panagiotis K. Evolution in men's volleyball skills and tactics as evidenced in the Athens 2004 Olympic Games. Int J Perf Anal Sport. 2005;5:1-8.

[4] Hughes M, Daniel R. Playing patterns of elite and non-elite volleyball. Int J Perf Anal Sport. 2003;3:5056.

[5] Zetou E, Tsigilis N, Moustakidis A, Komninakidou A. Playing characteristics of men's Olympic Volleyball teams in complex II. Int J Perf Anal Sport. 2006;6(1):172-177.

[6] Conti GC, Caetano RCJ, Ferreira NN, Junqueira G, Afonso J, Costa RP, Mesquita I. Determinants of attack tactics in Youth male elite volleyball. Int J Perf Anal Sport. 2011;11(1):96-104.

[7] Eom HJ, Schutz RW. Statistical analyses of volleyball team performance. Res Q Exerc Sport. 1992;63(1):11-18.

[8] Marcelino R, Mesquita I. Characterizing the efficacy of skills in high performance competitive volleyball. World Congress of Performance Analysis of Performance Hungary. 2006;7:491-496.

[9] Marcelino R, Mesquita I, Afonso J. The weight of terminal actions in volleyball. Contributions of the spike, serve and block for the teams' rankings in the World League 2005. Int J Perf Anal Sport. 2008;8(2):1-7.

[10] Bergeles N, Barzouka K, Nikolaidou ME. Performance of male and female setters and attackers on Olympic-level volleyball teams. Int J Perf Anal Sport. 2009;9:141-148.

[11] Monteiro R, Mesquita I. Marcelino R. Relationship between the set outcome and the dig and attack efficacy in elite male Volleyball game. Int J Perform Anal Sport, 2009;9:294-305.

[12] Katić R, Grgantov Z, Jurko D. Motor structures in female volleyball players aged 14-17 according to technique quality and performance. Collegium Antropologicum. 2006;1:103-112.

[13] HermosoA, García R,Carlos D, Saavedra JM. Discriminatory power of game-related statistics in 1415 year age group male volleyball, according to set. Percept Mot Skills. 2013;116:132-143. 
[14] Dopsaj M, Nešić G, Ćopić N. The multicentroid position of the anthropomorphological profile of female volleyball players at different competitive levels. Facta Universitatis, series: Physical Education and Sport. 2010;8(1):47-57.

[15] Bubanj S, Stanković R, Bubanj R, Dimić A, Bednarik J, Kolar E. One-leg vs two-leg vertical jumping performance. Facta Universitatis, series: Physical Education and Sport. 2010;8(1):89-95.

[16] Marques MC, Van Den Tillaar R, Gabbett TJ, Reis VM González-Badillo JJ. Physical fitness qualities of professional volleyball players: Determination of positional differences. J Strength Cond Res. 2009;23(4):1106-1111. doi: 10.1519/JSC.0b013e31819b78c4.

[17] Milić V, Nejić D, Kostić R. The effect of plyometric training on the explosive strength of leg muscles of volleyball players on single foot and two foot take off jumps. Facta Universitatis, series: Physical Education and Sport. 2008;6(2):169-179.

[18] Miskin MA, Fellingham GW, Florence LW. Skill Importance in women’s volleyball. J Quant Anal Sport. 2010;6(2):1-14.

[19] Gabbett T, Georgieff B, Anderson S, Cotton B, Savovic D, Nicholson L. Changes in skill and physical fitness following in talent-identified volleyball players. J Strength Cond Res. 2006;20(1):29-35.

[20] Dopsaj M, Ćopić N, Nešić G, Sikimić M. Jumping performance in elite female volleyball players relative to playing positions: a practical multidimensional assessment model. Serb J Sports Sci. 2012;6(2):61-69.

[21] Palao JM, Santos JA, Ureña A. Effect of team level on skill performance in volleyball. Int J Perf Anal Sport. 2004;4:50-60

[22] Lidor R, Ziv G. Physical characteristics and physiological attributes of adolescent volleyball players a review. Pediatr Exerc Sci. 2010;22(1):114-134. 